\title{
Unified European higher medical degrees
}

\author{
Lars H. Breimer and Dimitri P. Mikhailidis
}

Department of Chemical Pathology and Human Metabolism, Royal Free Hospital School of Medicine, Rowland Hill Street, London NW3 2PF, UK

Summary: Unequal access to higher medical degrees, which are important for career advancement, is a problem that is likely to plague UK medicine as integration within Europe proceeds. This paper analyses the characteristics of M.D.s at the Royal Free Hospital School of Medicine and proposes a solution of creating a common European doctorate.

\section{Introduction}

Two years ago in the British Medical Journal the late Ralph Johnson drew attention to the inequitable regulations governing eligibility for higher medical degrees in UK universities. ${ }^{1}$ For example, one university did not admit graduates of other universities in any circumstance and another only under almost as restricted criteria. He concluded that these differences in entry requirements 'may put some foreign graduates at a disadvantage' and that 'this problem may become more severe as the number of graduates from the European Community who settle in Britain increases.. ${ }^{1}$ At the same time we were looking for a solution to this problem but approaching it through the exit requirements, that is the assessment of the candidates' work. ${ }^{2}$

How can research degrees from different European countries be compared? We proposed that a common European thesis system could be based on publications. ${ }^{2,3}$ During our investigations we discovered that the Oxford D.M., one of the degrees whose eligibility is most restricted, ${ }^{1}$ can be obtained by published work and a brief, optional (2,000 word) essay. The International Union of Biochemistry (IUB) and International Union of Immunological Societies (IUIS) have issued guidelines for doctorates ${ }^{4,5}$ stating that a thesis should be judged by whether the material has been published or is of a publishable standard. Indeed, a British study has reported that theses with papers are likely to be the best, because among UK doctoral candidates there is a direct correlation between publishing and submitting their theses promptly; stragglers and those failing to submit

Correspondence: L.H. Breimer, M.A., M.D.

Accepted: 30 October 1993 have few or no publications. ${ }^{6}$ The thesis could be based on either tomes or publications, but for the latter option each paper must be thoroughly reviewed and set in context. Such systems already operate in Holland, Japan and Sweden. ${ }^{2}$ Thus, the questions arise as to whether publication-based theses are feasible for all UK universities while maintaining standards. To begin to answer these questions we compared successful M.D.s and Ph.D.s at a medical college of the University of London.

\section{Methods}

To assess the IUB and IUIS criteria for doctorate standards ${ }^{4,5}$ we examined the successful M.D.s and Ph.D.s submitted at the Royal Free Hospital School of Medicine between 1968 and 1992. The quality of the journals included in the theses was assessed by the Science Citation Index (SCI). ${ }^{7}$ Briefly, the SCI assesses the impact of an article by how often it is cited. This is used to compute an impact factor and thereby a rank for the journal of publication, corrected for frequency of issue. The better the journal, the higher its impact value and lower its rank. For example in 1988 the impact values and ranks were: $N$ Engl J Med 21.148 \& 7; Nature 15.758 \& 14; Lancet 14.480 \& 17; JAMA $5.283 \& 86$ and the $B r M e d J 3.136 \& 232$. The limitations of the SCI are discussed at length elsewhere $^{8-11}$ and reviewed in reference 7. However, these figures illustrate that it favours US over British journals (which in turn outrank European journals). Also, small changes in impact factor result in marked changes in rank especially above rank $1,000 .^{7}$ Because of this median ranks were calculated on journals ranked $\leqslant 1,000$. Despite the 
limitations, the SCI remains an independent yardstick to assess journals and has been used to advise hospitals on stocking libraries ${ }^{12}$ and by the Universities Funding Council to allocate research funding in UK universities. ${ }^{13}$

A detailed report on UK Ph.D.s as compared with Swedish doctorates is published elsewhere. ${ }^{7}$ Swedish doctorates are based on publications and the regulations are the same for M.D.s and Ph.D.s; the basic degree of the candidate determines the title.

\section{Results}

The results of our assessment of the doctorates are summarized in Tables I and II. Median ranks were calculated on the journals ranking $\leqslant 1,000$ because $>1,000$ small changes in impact factor result in marked changes in rank (see above and reference 7).

A total of 56 M.D.s (tome-based) were compared with 61 UK Ph.D.s which contained papers and were from our medical school, and 69 Swedish doctoral theses (publication-based). We have previously shown that $30 \%$ of UK Ph.D. theses contained papers, ${ }^{2}$ in the present survey $62 \%$ of the M.D.s had papers. The median number of papers in the M.D.s were four, identical to the figure for Swedish (publication-based) doctorates. ${ }^{7}$ The Ph.D.s had a lower median number of papers of two.

\section{Polyauthorship-a myth}

The median number (range) of authors per paper included in these theses was: UK M.D. four (1-9), UK Ph.D. four $(1-10)$ and Swedish doctorates three $(1-10)$. A limited survey of ten randomly selected issues of the Lancet in 1992 showed that there were six $(1-18)$ authors per original paper, a figure which is consistent with that of six reported by Epstein for the Lancet for 1989-1991 as part of his study of eight major journals. ${ }^{14}$
Table I Analysis of authorship characteristics of papers used to support doctoral theses

\begin{tabular}{lrrr}
\hline & \multicolumn{2}{c}{ British } & $\begin{array}{c}\text { Swedish } \\
\text { doctorate* }\end{array}$ \\
& M.D. & Ph.D. & \\
& 56 & 61 & 69 \\
$\begin{array}{l}\text { Number of theses } \\
\quad \text { with papers }\end{array}$ & 197 & 175 & 283 \\
$\begin{array}{l}\text { Total number of papers } \\
\text { Number of papers per }\end{array}$ & & & \\
$\quad$ theses with papers & 4 & 2 & 4 \\
$\quad \begin{array}{l}\text { Median } \\
\text { Range }\end{array}$ & $1-9$ & $1-8$ & $1-7$ \\
$\begin{array}{l}\text { Number of authors } \\
\quad \begin{array}{l}\text { Median } \\
\text { Range }\end{array}\end{array}$ & 4 & 4 & 3 \\
$\begin{array}{l}\text { Candidate as first } \\
\quad \text { or sole author (\%) }\end{array}$ & $1-9$ & $1-10$ & $1-10$ \\
\end{tabular}

*Adapted from reference 7 .

\section{Contribution to work}

The candidate was the first and/or sole author of $88 \%$ of the papers in the M.D.s, as compared with $66 \%$ among Ph.D.s (Table I). This compares with $77 \%$ for Swedish doctorates where qualification is on the basis of published work. ${ }^{7}$

\section{Standards maintained}

The British Ph.D. had a median rank of 218 and the M.D. achieved 271. The Swedish system, which is publication-based, achieved $224 .^{7}$ These ranks correspond to impact factors of 3.172, 2.847 and 3.161, respectively. When ranking up to 1,000 was considered for journals used twice or more (a more representative sample of usage), the percentage of papers was similar for UK M.D.s (61\%) and Ph.D.s (59\%); $49 \%$ of papers in Swedish doctorates were in this top quartile of the citation index. Of all the papers included in these theses, the proportion which could readily be identified as 'British' was $29 \%$ for UK M.D.s and $19 \%$ for UK

Table II Ranking and use of journals where papers included in the theses were published

\begin{tabular}{lccc}
\hline & \multicolumn{2}{c}{ British } & \multirow{2}{*}{$\begin{array}{c}\text { Swedish } \\
\text { doctorates }\end{array}$} \\
& M.D. & Ph.D.* & \\
\hline Median ranking of journals used twice & 271 & 218 & 224 \\
$\quad$ or more and ranking $\leqslant 1,000$ & & & \\
Use (as \% of all) & 12 & 10 & 14 \\
$\quad$ Ranking $\leqslant 100$ used at all & 16 & 32 & 26 \\
Ranking $\leqslant 200$ used at all & 61 & 59 & 49 \\
Ranking $\leqslant 1,000$ used twice or more & 61 & \\
\hline
\end{tabular}

*Adapted from reference 7 . 
Ph.D.s, but only 3\% for Swedish doctorates. Also, of all papers published in journals ranking 200 or better, more 'British' journals were used by the UK than Swedish theses - UK M.D. 66\%, UK Ph.D. $41 \%$ and Swedish doctorates $4 \%$.

\section{Discussion}

The purpose of this study was to audit the successful M.D. theses presented at our medical school. We then compared our findings with those of our earlier study of Ph.D.s and M.D.s from Sweden. ${ }^{7}$

The standards of work submitted with these M.D. theses was high. One objection to publication-based doctoral systems is that they lead to multiple authorship. Our findings do not support this but instead they indicate a positive effect on authorship. Our data also demonstrate that it is unlikely that different candidates would use the same paper to support their theses.

These M.D.s had a higher publication rate than the Ph.D.s. Although it was achieved at the expense of publishing in journals with a lower ranking, nevertheless this represented only a $10 \%$ fall in impact factor. Therefore, the increase in papers in the M.D.s was not at the expense of quality. Indeed, these three thesis systems have a large proportion of papers published in journals ranking in the top quartile (that is, ranking up to 1,000 out of 4,233) (Table II). The small differences between the Swedish and UK theses are probably explained by: (1) British journals having a high citation rate ${ }^{7-9}$ and (2) the UK theses being a biased sample because they are likely to be of a higher standard than those without publications. ${ }^{6}$

Non-homogeneous regulations for research

\section{References}

1. Johnson, R. Requirements of British universities for higher medical degrees. Br Med J 1991, 302: 397-399.

2. Breimer, L.H. \& Mikhailidis, D.P. A thesis for all seasons. Nature 1991, 353: 759-760.

3. Breimer, L.H. \& Mikhailidis, D.P. An MD for Europe? Br J Hosp Med 1993, 49: 459-460.

4. Anonymous. Standards for the Ph.D. degree in biochemistry and molecular biology. FASEB J 1989, 3: 2106-2110 and Trends Biochem Sci 1989, 14: 205-209.

5. Revillard, J.-P. \& Celach, F. Guidelines for the Ph.D. degree in immunology. Immunol Today 1992, 13: 367-373.

6. Rudd, E. A New Look at Postgraduate Failure. SRHE \& NFER-Nelson, University of Surrey, Guildford, 1985, pp. 2-4.

7. Breimer, L.H. \& Mikhailidis, D.P. Towards a doctoral thesis based on published works. Biomed Pharmacother 1993, 47: 403-407. degrees in terms of criteria for eligibility are a problem for doctors in training. ${ }^{1}$ We found that there are also differences in their assessment. Consequently, we propose the introduction throughout Europe of standardized European Science Doctorates (ESD) and European Medical Doctorates (EMD).

Eligibility for these degrees should be independent of where the first degree was taken. They will probably need to be publication-based to comply with a common standard. Here we show that it is feasible to allow M.D.s to be examined in publication-based mode. We have previously suggested from a separate assessment of Ph.D.s that it could be used for them too. ${ }^{7}$ However, having since identified a study reporting that UK theses containing publications are generally of a higher quality than those without ${ }^{6}$ that recommendation may need some revision.

The advantages of a publication-based system have been discussed. ${ }^{2,3}$ Briefly, a 5,000-8,000 word overview together with papers saves time from the mechanics of assembling a tome, a cost-effective way for a research group to operate. The candidate is free to spend time on research and learns how to publish a paper. Were the overviews to be published in an international thesis journal they would be widely available. If that journal also announced forthcoming theses, then it would reduce research overlap. The public examination of candidates ensures fairness and dissemination of knowledge. Bringing together examiners from several countries would promote international collaboration.

Ralph Johnson desired equal opportunity to a career advantage; hopefully our findings further his arguments.

8. Ernst, E. \& Kienbacher, T. Chauvinism. Nature 1991, 352: 560.

9. Henrissat, B. National publication bias. Nature 1991, 354: 427.

10. King, J.A. A review of bibliometric and other science indicators and their role in research evaluation. $J$ Info Sci 1987, 13: $261-276$.

11. Squires, B.P. Citation rate: a measure of excellence? Can Med Assoc J 1992, 146: 341.

12. Huth, E.J. A library for Internists VI: recommendations from the American College of Physicians. Ann Intern Med 1988, 108: 497-512.

13. Abbott, A. Better luck second time? Nature 1992, 356: 278.

14. Epstein, R.J. Six authors in search of a citation: villains or victims of the Vancouver convention? Br Med J 1993, 306: $765-767$ 